\title{
The Effect of Charge State and the Localization of Charge on the Collision-Induced Dissociation of Peptide Ions
}

\author{
Kevin M. Downard and Klaus Biemann. \\ Department of Chemistry, Massachusetts Institute of Technology, Cambridge, Massachusetts, USA
}

\begin{abstract}
The effect that charge state has on the collision-induced dissociation (CID) of peptide ions is examined in detail for several representative peptides under high-energy collision conditions. The CID spectra of singly and doubly charged precursor ions (generated by fast-atom bombardment and electrospray ionization, respectively) are compared for several peptides with similar primary structure. It is shown that for peptides that contain highly basic amino acids, the dissociation of doubly charged ions is strongly influenced by the position of these residues within the peptide and the general observations reported concerning the dissociation of singly charged ions can be extended to precursors with higher charge states. Based on the dissociation behavior of the doubly charged ions of these peptides, it is demonstrated that two charges can reside in close proximity in the precursor ions, overcoming possible repulsion effects, when favored by a high concentration of basic sites. In addition, this work illustrates that in the case of doubly charged ions, the charge state of some fragment ions can be determined directly from the mass-to-charge ratio assignments of the CID spectrum. ( $($ Am Soc Mass Spectrom 1994, 5, 966-975)
\end{abstract}

$\mathrm{T}$ The use of mass spectrometry to determine the primary structure of peptides has, to date, typically involved collision-induced dissociation (CID) of their protonated singly charged ions $[\mathrm{M}+\mathrm{H}]^{+}$ generated by fast-atom (or ion) bombardment (FAB) ionization [1, 2]. This approach, however, is restricted to peptides of molecular weight below 3000, because this mass is the limit at which singly charged ions can be efficiently dissociated during the collisional activation process. It has been reported that when singly charged peptide ions with energies of $8 \mathrm{keV}$ are collided with a helium target gas, the energy available for dissociation of the ion increases with its mass to a maximum at approximately $1400 \mathrm{u}$ and then decreases [3].

The recent development of electrospray ionization (ESI) [4] has allowed much larger molecules to be ionized than was previously possible [5]. More importantly, the technique achieves this through the formation of multiply charged ions, where molecules are detected over a limited mass-to-charge range at integral fractions of their mass [6]. Multiply charged ions, by definition, have higher kinetic energies than their singly charged counterparts when accelerated with the same potential. Consequently, more energy is available for electronic and vibrational excitation of these ions during the collision process, which together with the

Address reprint requests to Professor Klaus Biemann, Department of Chemistry, Roun 56-010, Massachusitts Institute of Technology, Cambridge, MA 02139-4307. ion's predicted instability due to coulombic repulsion forces facilitates the dissociation of much larger molecules [7]. We refer to CID in this context as the process used to dissociate ions in a field-free region of the spectrometer by their collision with an inert target gas. The same terminology also has been used to describe a different process; namely, the dissociation of ions accelerated across a potential difference in the high pressure region of the ion source [8].

With few exceptions, most studies of the CID of multiply charged peptide ions to date have been performed under low-energy conditions on triple quadrupole instruments [7, 9-12], although some progress has been made by employing an ion cyclotron resonance mass spectrometer [13]. Multisector mass spectrometers offer several features that extend the range of experiments possible with triple quadrupole instruments: (1) a larger mass-to-charge ratio range, (2) higher resolution, and (3) the ability to dissociate ions at high (kiloelectronvolt) collision energies. It is noteworthy that although a precursor ion of a large molecule is detected at a mass-to-charge ratio that is a fraction of its molecular weight, it is necessary during a tandem CID experiment to scan the serond mass spectrometer (MS-2) to include the $\left[\mathrm{M}+\mathrm{H}^{+}\right.$ion to collect all of the possible product ions. In addition, although it is generally considered desirable to transmit all isotopes of the multiply charged precursor ion by operating the first spectrometer (MS-1) at low resolution, the isotope peaks of the product ions should be resolved, at least partially, so that their charge states 
can be assigned. This requires that the MS- 2 of the tandem instrument achieve a resolution close to that of the analyte's molecular weight. These factors restrict the use of triple quadrupole instruments to studies of the dissociation of multiply charged ions of analytes with molecular weights less than 2000. Magnetic sector tandem instruments, by comparison, can in principle be used to study the collision-induced dissociation of multiply charged ions of analytes to approximately $10,000 \mathrm{u}$.

The earliest studies of the high-energy CID of multiply charged ions of peptides performed on sector instruments were those generated by field desorption and $F A B$ ionization under favorable experimental conditions $[14,15]$. We [16] and others [17-19], however, have been investigating the CID of multiply charged ions of peptides produced by electrospray ionization on tandem-sector mass spectrometers. To date, we have directed our efforts to the dissociation of multiply charged ions of small peptides $(<1500 u)$ for several reasons. First, the electrospray ionization process is concentration dependent; that is, the total ion current measured for all the multiply charged ions detected increases proportionally with the concentration of the analyte in solution to a maximum, which has been found to be on the order of $250 \mu \mathrm{M}$ [20]. However, the ion current associated with any one charge state of a large molecule is less than that for a multiply charged ion of a small molecule where generally only one charge state predominates. Achieving the desired ion current to perform a CID experiment is therefore more difficult for a multiply charged ion of a large molecule over that of a small molecule. Second, this constraint is compounded by the need for higher resolution (achieved at the expense of ion transmission) to resolve the isotopes of product ions formed from a large molecule over those from a small molecule where few charge states are possible. Finally, because little is known of the fragmentation behavior of multiply charged ions of small peptides under high-energy conditions, it seens prudent to restrict our investigations at this stage to the smaller molecules.

It is generally accepted that the singly charged ions $[\mathrm{M}+\mathrm{H}]^{+}$of peptides generaled by FAB represent the neutral peptide molecule with one proton attached. This form is favored over ions that contain several charges (positive and negative), chiefly on the amino acid side chains, where the net charge is +1 because peptides invariably give rise solely to a single positively charged species regardless of their size or primary sequence. When collisionally activated, the product ions produced from these species are dependent in part on the structure of the peptide, particularly on the location of basic amino acid residues [21]. Indeed that report suggested that the proton is reasonably localized in a $[\mathrm{M}+\mathrm{H}]^{+}$precursor ion of a peptide that contains a basic residue(s), and that the product ions produced by high-energy CID are formed through "charge-remote" processes. This is not to say that all of the $[\mathrm{M}+\mathrm{H}]^{+}$ions produced by FAB represent a single discrete structure. Instead, for a peptide with one or more basic groups, a high proportion of precursor ions have the charge more localized at those groups whereas the charge is more widely distributed in the case of a peptide without a basic site. Under high-energy conditions, a relationship between the location of the charge in the singly charged peptide precursor ion and the nature of the fragment ions observed has been reported [21]. The fragmentation behavior of peptides that contain several charges, however, has not been studied under high-energy conditions in any detail.

This study examines the effect that the charge state of the peptide precursor ion has on its dissociation by systematically comparing the fragmentation behavior of FAB-generated $[\mathrm{M}+\mathrm{H}]^{+}$and electrospray-generated $[\mathrm{M}+2 \mathrm{H}]^{2+}$ ions for several basic peptides of similar primary structure. The results are discussed with respect to the localization of charge in each of the precursor ions and, where appropriate, are compared with those reported under low-energy collision conditions.

\section{Experimental}

The CID mass spectra of the doubly charged peptide ions were acquired on a JEOL (Akishima, Japan) HX110/ HX110 tandem four-sector mass spectrometer of $E_{1} B_{1} L_{2} B_{2}$ geometry fitted with a commercial Analytica of Branford (Branford, CT) electrospray ion source (model 101490) represented schematically in Figure 1 . The peplides were dissolved at a concentration of $250 \mu \mathrm{M}$ in a solution of methanol:water:acetic acid ( $49: 49: 2$ by volume). The solutions were infused through the electrospray needle at a rate of $0.5 \mu \mathrm{L} / \mathrm{min}$ with a Harvard Apparatus (Natick, MA) syringe pump (model 551111). A stream of nitrogen gas heated initially to $180^{\circ} \mathrm{C}$ was passed counter to the spray to desolvate the droplets, which were then focused onto the glass capillary. The potentials applied to the spray
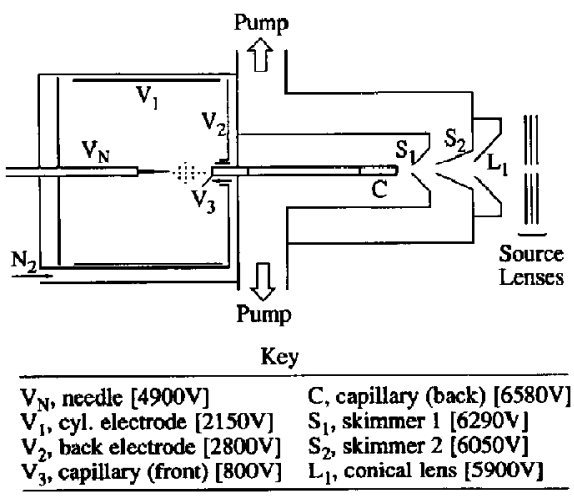

[Typical source potentials in parentheses]

Figure 1. Schematic representation of the electrospray ion source (not drawn to scale). 
region of the source were provided by an Analytica of Branford power supply (model 100581). The remaining source potentials were provided by a power supply built in this laboratory. No modifications were made to the ion source with the exception that a capillary of reduced inner diameter $(300 \mu \mathrm{m})$ was fitted to decrease the pressure throughout the ion source to minimize scattering of the ion beam. Typically, a pressure of $1 \times 10^{3} \mathrm{~Pa}$ was maintained in the ion source of the mass spectrometer. The doubly charged ions were accelerated at a potential dictated by that of the first skimmer $(\sim 6 \mathrm{kV})$. 'The slits of the MS-1 were set to approximate a resolution of between 1:200 and 1:500 to at least partially transmit the ${ }^{13} \mathrm{C}$ component of the isotopic envelope. The collision cell was floated at $2 \mathrm{kV}$ above ground to satisfy the derived scan law $[22,23]$ and improve transmission of the low mass fragments. Helium gas was introduced into the collision cell in the third field-free region at a pressure sufficient to reduce the primary beam by $\sim 70 \%$. The slits of the MS-2 were set to approximate a resolution of 1:1000. The doubly charged ion spectra represent the sum of five to twelve 30-s scans that correspond to the consumption of 300-800 pmol of peptide. All mass-tocharge ratio assignments for the fragment ions represent monoisotopic $\left({ }^{12} \mathrm{C}\right.$-only) values unless otherwise stated. The CID spectra of the singly charged ions were recorded by using conditions that have been reported in detail elsewhere [24]. The CID spectra of the doubly charged precursor ions have a lower signal-to-noise ratio than the spectra of the singly charged precursors primarily because of the lower amounts of sample introduced in the ESI source at any time, which results in correspondingly lower precursor ion currents for the $[\mathrm{M}+2 \mathrm{H}]^{2+}$ species.

The trimethylammoniumacetyl (TMAA) derivatives of des- $\mathrm{R}^{9}$-bradykinin and bradykinin were prepared through modification of a reported procedure [25]. Briefly, the peptides were dissolved in excess chloroacetyl chloride and incubated at $37{ }^{\circ} \mathrm{C}$ for $2 \mathrm{~h}$. The solvent was removed in vacuo and trimethylamine (25\% in water) was added. The solution was heated again at $37{ }^{\circ} \mathrm{C}$ for $2 \mathrm{~h}$ and the solvent was removed in vacuo. The crude products were analyzed directly.

\section{Results and Discussion}

\section{Bradykinin}

The CID spectrum of the electrospray-generated [M + $2 \mathrm{H}]^{2+}$ ion of bradykinin is shown in Figure 2 together with that for the $[\mathrm{M}+\mathrm{H}]^{+}$ion produced by $\mathrm{FAB}$. Despite the difference in the charge state of the precursors, the fragment ions observed are quite similar. Although $a_{n}$ ions are more abundant in the spectrum of the $[\mathrm{M}+\mathrm{H}]^{+}$ion and $z_{n}+1$ ions are more prevalent in the spectrum of the doubly charged precursor, both spectra exhibit a series of $a_{n}\left(a_{1}+1, a_{3}, a_{5}, a_{6}, a_{7}\right.$, and $\left.a_{8}\right), d_{n}\left(d_{6}, d_{8}\right.$, and $\left.d_{9}\right), w_{n}\left(w_{3}, w_{4}, w_{7}\right.$, and $\left.w_{8}\right)$,

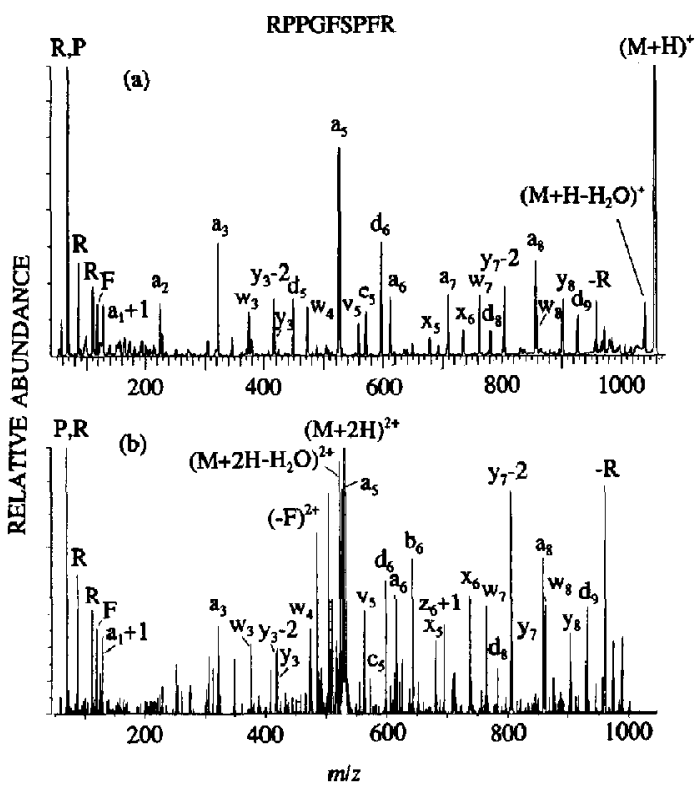

Figure 2, CID spectra of (a) the $[M+H]^{+}$and (b) the $[M+$ $2 \mathrm{H}]^{2+}$ ions of bradykinin.

$x_{n}\left(x_{5}\right.$ and $\left.x_{6}\right)$, and $y_{n}\left(y_{3}, y_{3}-2, y_{7}, y_{7}-2\right.$, and $\left.y_{8}\right)$ ions. Because the CID spectrum of the doubly charged precursor ion exhibits mainly singly charged product ions and the product ions of each spectrum are of the $\mathrm{N}$ - and $\mathrm{C}$-terminal type, these similarities likely reflect that a high proportion of $[\mathrm{M}+\mathrm{H}]^{+}$precursor ions have either of two forms in which the proton resides near or at the $\mathrm{N}$ - or $\mathrm{C}$-terminus (and the CID spectrum represents a composite of fragment ions from each form), whereas the $[\mathrm{M}+2 \mathrm{H}]^{2+}$ precursor ions have predominantly a single structure in which one proton resides toward the $\mathrm{N}$-terminus and the other toward the C-terminus.

In view of the structure of bradykinin, these results are not unexpected. Bradykinin contains nine amino acids with two basic arginine residues, one at each terminus. Thus, the most stable form of the $[\mathrm{M}+2 \mathrm{H}]^{2+}$ ion that minimizes coulombic repulsion between like charges is one in which the first proton is bound toward the $\mathrm{N}$-terminus (on the $\mathrm{N}$-terminal amino group or on the side chain of arginine at position 1) and the second proton is localized on the side chain of the arginine residue at the $\mathrm{C}$-terminus.

The major differences between the two spectra occur in the region of the precursor ions of each spectrum and in the presence of a single predominant $b_{6}^{+}$ ion $\left(m / z\right.$ 642) in the CID spectrum of the $[\mathrm{M}+2 \mathrm{H}]^{2+}$ precursor, which is absent from that of the singly charged ion. The significance of this ion and a mechanism for its formation are discussed later in light of the results for the remaining peptides.

It is of interest at this point to compare the CID spectrum of the doubly charged ion of bradykinin 
recorded at a high collision energy (Figure $2 b$ ) with that reported at low energy [12]. These two spectra differ substantially. The low-energy spectrum [12] is dominated by a series of complementary $b_{n-}$ and $y_{n}$ type ions, which implies that one proton is bound toward the $\mathrm{N}$-terminus while the second proton is delocalized along the peptide backbone affecting cleavage. This spectrum also exhibits both $\mathrm{N}$ - and $\mathrm{C}$-terminal fragment ions formed from cleavage of the peptide backbone with the loss of a molecule of ammonia.

The high-energy spectrum (Figure $2 b$ ) on the other hand, exhibits fragments of many ion types that (as rationalized above) are produced by charge-remote fragmentation processes. These fragment ions include those formed from cleavage of the amino acid side chains, which are only observed at these collision energies [21]. Both spectra, however, contain sufficient ions to elucidate the structure of the precursor with the possible exception of the proline residue at position 7 (note the absence of fragment ions formed through cleavage at the C-terminal side of this residue).

\section{des- $R^{\prime}$-Bradykinin}

The CID spectra of the $[\mathrm{M}+2 \mathrm{H}]^{2+}$ and $[\mathrm{M}+\mathrm{H}]^{+}$ ions of des- $\mathrm{R}^{1}$-bradykinin (Figure 3 ) also are quite similar; both exhibit fragment ions of the $a_{n}\left(a_{2}, a_{4}, a_{6}\right.$, and $\left.a_{7}\right), v_{n}\left(v_{2}\right.$ and $\left.v_{5}\right), w_{n}\left(w_{3}, w_{4}\right.$, and $\left.w_{7}\right), x_{n}\left(x_{5}\right.$ and $\left.x_{6}\right), y_{n}\left(y_{3}-2, y_{7}-2\right.$, and $\left.y_{7}\right), z_{n}\left(z_{2}+1\right.$, $z_{5}+1, z_{6}+1$, and $z_{7}+1$ ) type. The C-terminal fragment ions are prevalent in both spectra, though more so for the singly charged precursor, which is consistent

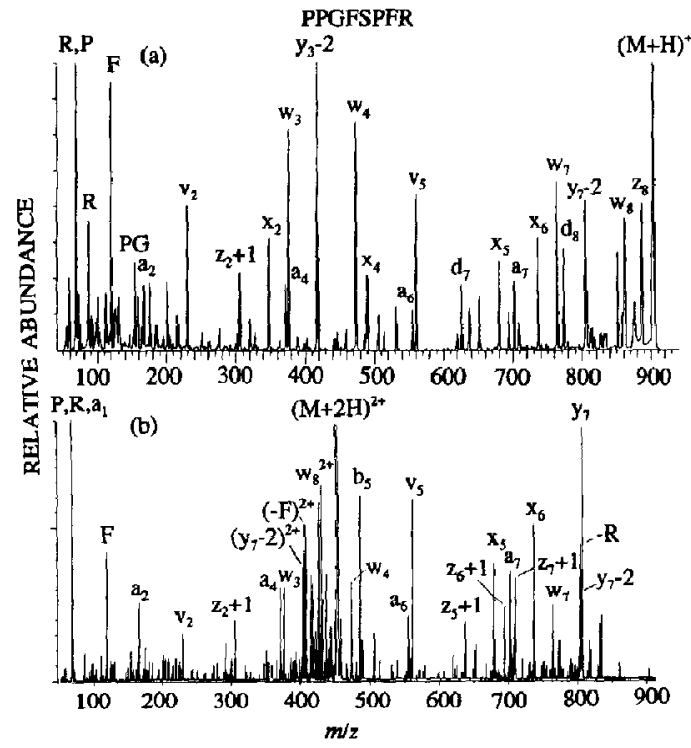

Figure 3. CID spectra of (a) the $[\mathrm{M}+\mathrm{H}]^{+}$and (b) the $[\mathrm{M}+$ $2 \mathrm{H}]^{2+}$ ions of des-R $\mathrm{R}^{1}$-bradykinin. with a higher proportion of precursor ions that contain the proton bound to the side chain of the arginine over the N-terminal amino group. Differences in the spectra occur in the region of the precursor ions and in the presence of a $b_{5}^{+}$ion in the spectrum of the doubly charged precursor, in analogy with the $b_{6}^{+}$ion observed for bradykinin.

Once again, the similarity of these spectra can be rationalized in terms of a high proportion of $[\mathrm{M}+\mathrm{H}]^{+}$ ions that have two forms, with the proton either localized on the N-terminal amino group or on the side chain of the C-terminal arginine residue. The dominance of the C-terminal fragment ions in this spectrum (Figure 3a) would suggest that most precursors have the latter structure. The $\mathrm{CID}$ spectrum of the $[\mathrm{M}+\mathrm{H}]^{+}$ ions, however, still represents a composite of fragments produced from either form. The $[\mathrm{M}+2 \mathrm{H}]^{2+}$ ions have mainly one form, where the charges reside on either end of the molecule at these basic sites. This Iocalization of charge is again less apparent in precursor ions dissociated at low collision energies. The CID spectrum of the $[\mathrm{M}+2 \mathrm{H}]^{2+}$ ion of des- $\mathrm{R}^{1}$-bradykinin dissociated under low-energy conditions [11] differs markedly from that reported here at high energies (Figure 3b). The low-energy spectrum is dominated by $y_{n}$-type fragment ions rationalized by the initial loss of a proton from the precursor ion to yield a singly charged ion, which subsequently dissociates through charge-directed fragmentation processes [11].

\section{des- $R^{9}$-Bradykinin}

In contrast to the sets of spectra compared to this point, the high-energy CID spectra of the $[\mathrm{M}+\mathrm{H}]^{+}$ and $[\mathrm{M}+2 \mathrm{H}]^{2+}$ ions of des- $\mathrm{R}^{9}$-bradykinin are quite different (Figure 4). The spectrum of the singly charged precursor ion is dominated by a series of $a_{n}$ and $d_{n}$ product ions consistent with a highly localized charge toward the $\mathrm{N}$-terminus [21]. The CID spectrum of the $[\mathrm{M}+2 \mathrm{H}]^{2+}$ ion, however, is dominated by singly charged fragment ions of the $b_{n}$ type and a $y_{2}^{+}$ion at $m / z$ 263. Clearly, in this case, if the argument for charge localization holds, the two charges do not reside at the most basic sites of the peptide (i.e., the $\mathrm{N}$-terminal amino group and the side chain of arginine) in a large fraction of the doubly charged precursor ions. Instead, the occurrence of fragment ions of the $b_{n}$ and $y_{n}$ type suggests that a high proportion of precursor ions have one proton bound toward the $\mathrm{N}$-terminus, while the second is delocalized along the peptide backbone. The predominance of the $y_{2}^{+}$fragment and its complementary $b_{6}^{+}$ion would suggest that some precursor ions have one proton localized near the $\mathrm{N}$ terminus and the second bound to the nitrogen of the proline residue at position 7 . Indeed, the cleavage of the amide bond that precedes proline at position 7 appears to be sufficiently facile that it occurs at the expense of additional sequence information. The $y_{2}^{+}$and $b_{6}^{+}$ions also dominate the CID 


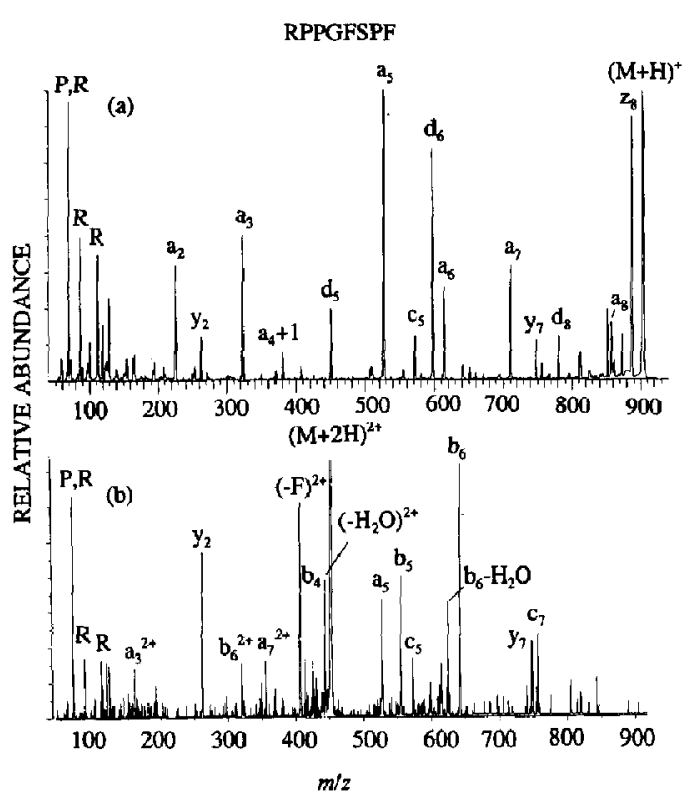

Figure 4. CID spectra of (a) the $[\mathrm{M}+\mathrm{H}]^{+}$and (b) the $[\mathrm{M}+$ $2 \mathrm{H}]^{2+}$ ions of des- $\mathrm{R}^{9}$-bradykinin.

spectrum of the $[\mathrm{M}+2 \mathrm{H}]^{2+}$ ion recorded under lowenergy conditions [12] and, in this case, the spectra produced in the high- and low-energy regime are similar in appearance. This supports the hypothesis that the second proton of the $[\mathrm{M}+2 \mathrm{H}]^{2+}$ ion is somewhat delocalized along the peptide backbone.

The presence of weak ion signals that correspond to the doubly charged fragments $a_{3}^{2+}, b_{6}^{2+}$, and $a_{7}^{2+}$ in the high-energy spectrum (Figure $4 \mathrm{~b}$ ) may indicate that, at least in some of the precursor ions, the two protons are located toward the N-terminus or that the bond cleavages that lead to these ion types are produced in part through heterolytic bond scission such that the fragments bear a charge at their C-termini.

\section{TMAA Derivatives}

In an attempt to generate a doubly charged precursor ion in which both charges are localized in close proximity at the $\mathrm{N}$-terminus, we prepared the $\mathrm{N}$ terminal TMAA derivative of des- $R^{9}$-bradykinin. The TMAA group is incorporated exclusively at the $\mathrm{N}$-terminus of a peptide that does not contain a lysine residue [25]. The ESI mass spectrum of this compound in a solution containing $2 \%$ acetic acid (pH 4) is shown in Figure 5a. The spectrum is dominated by the singly charged cation $\mathrm{M}^{+}(m / z 1003.2)$ in addition to cleavage products at $m / z 672.2$ and 856.4, most likely formed from the hydrolysis of the modified peptide in solution. Importantly, no $[\mathrm{M}+\mathrm{H}]^{2+}$ ion (i.e., protonated $\mathrm{M}^{+}$) at $\mathrm{m} / \mathrm{z} 502.3$ (calculated) is observed, and the spectrum remains unchanged as the $\mathrm{pH}$ of the solution is low-

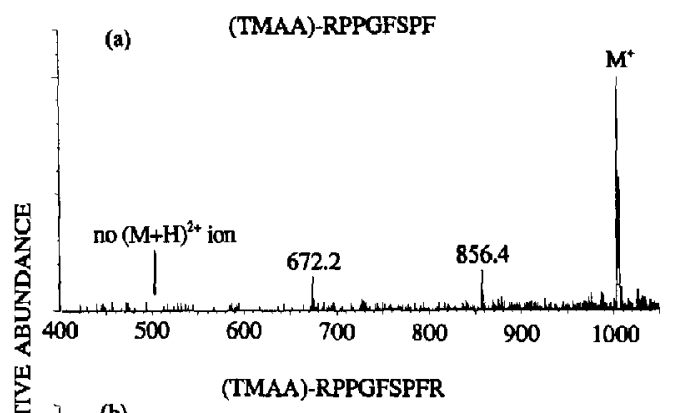

(b)

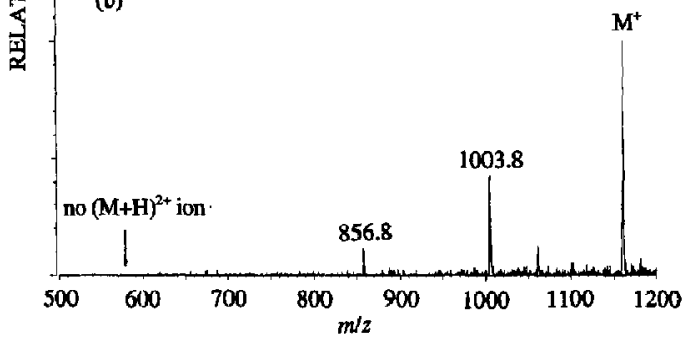

Figure 5. ESI mass spectra of (a) N-trimethylammoniumacetyldes- $\mathrm{R}^{9}$-bradykinin and (b) N-trimethylammoniumacetylbradykinin. (Note that in these spectra the notation $[\mathrm{M}+\mathrm{H}]^{2+}$ refers to $\left[\mathrm{M}^{+}+\mathrm{H}^{+}\right]$.)

ered (to $\mathrm{pH}$ 2). More surprisingly, the $[\mathrm{M}+\mathrm{H}]^{2+}$ ion also is absent from the spectrum for the TMAA derivative of bradykinin itself, where again the $M^{\prime}$ ion predominates (Figure 5b). These results might suggest that the TMAA group prevents further protonation of these peptides. However, because $[\mathrm{M}+\mathrm{H}]^{2+}$ ions have been observed for precharged peptide derivatives at low ionization energies by ESI [26] and at high ionization energies in a low pressure $\mathrm{FAB}$ source [27], it appears that any high energy $[\mathrm{M}+\mathrm{H}]^{2+}$ ions formed in these experiments are charge-stripped in the high pressure region of our ESI source prior to detection.

\section{$R^{0}, H y P^{3}, F^{7}$-Bradykinin}

To determine whether a higher proportion of basic sites toward the $\mathrm{N}$-terminus of an underivatized peptide could result in the localization of both charges in this region, sufficient to overcome possible repulsion effects, the CID spectra of the peptide RRP(HyP)GFSFFR were recorded (Figure 6). This peptide contains three highly basic groups at its $\mathrm{N}$ terminus; namely, the $\mathrm{N}$-terminal amino group and the side chains of the arginine residues at positions 1 and 2. The CID spectrum of the $[\mathrm{M}+\mathrm{H}]^{+}$ion of RRP(HyP)GFSFFR (Figure 6a) exhibits a prominent series of N-terminal fragment ions; notably, partial $a_{n}$ $\left(a_{2}+1, a_{4}, a_{6}, a_{7}, a_{8}\right.$, and $\left.a_{9}\right)$ and $d_{n}\left(d_{2}, d_{6}, d_{7}, d_{8}\right.$, $d_{9}$, and $d_{10}$ ) series of ions. These ions are commensurate with a highly localized charge toward the $\mathrm{N}$ terminus in a high proportion of the precursor ions [21]. 


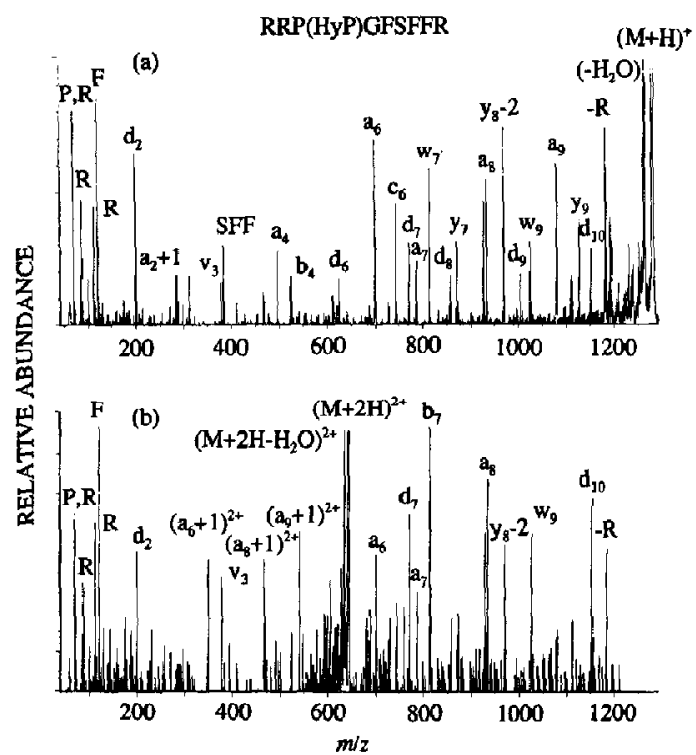

Figure 6. CID spectra of (a) the $[\mathrm{M}+\mathrm{H}]^{+}$and (b) the $[\mathrm{M}+$ $2 \mathrm{Hl}^{2+}$ ions of peptide RRP(HyP)GFSFFR.

The CID spectrum of the doubly charged precursor ion (Figure 6b) generated by ESI also is dominated by N-terminal fragment ions favored for precursor ions with a high concentration of basic groups at their N-terminus. Interestingly, the $\left(a_{n}+1\right)^{2+}$ ions at residues 6,8 , and 9 can arise only from precursors in which both protons are retained in the fragment ion. In addition, cleavage of the $\mathrm{C}-\mathrm{C}(\mathrm{O})$ bonds must proceed homolytically with no transfer of hydrogen to the C-terminal portion for the mass (and charge) of these ions to match that predicted. These species are then restricted to one of the structures shown in Figure 7.

One might argue that if the two charges do remain localized in the $[\mathrm{M}+2 \mathrm{H}]^{2+}$ precursor ions of peptide RRP(HyP)GFSFFR that lead to these fragments, they may still be separated by at least six residues because the smallest such fragment that bears two charges is the $\left(a_{6}+1\right)^{2+}$ ion. It is important to note, however, that ions of this type were not observed in the CID spectrum of the doubly charged precursor of bradykinin. Because these peptides differ in structure at the first six residues by the presence of an additional arginine at the N-terminus in the case of peptide RRP(HyP) GFSFFR, then it appears that in a proportion of the $[\mathrm{M}+2 \mathrm{H}]^{2+}$ precursor ions of this peptide the two charges reside in close proximity near the $\mathrm{N}$ terminus. Specifically, the protons are either bound to the adjacent arginine residues at positions 1 and 2 , or one proton is bound to the $\mathrm{N}$-terminal amino group and the second proton is bound to arginine at position 2 (Figure 7). This is despite the fact that another remote basic site, namely, the side chain of arginine at position 10 , is present. Whether these two charges reside toward the $\mathrm{N}$-terminus in the peptide in solution or

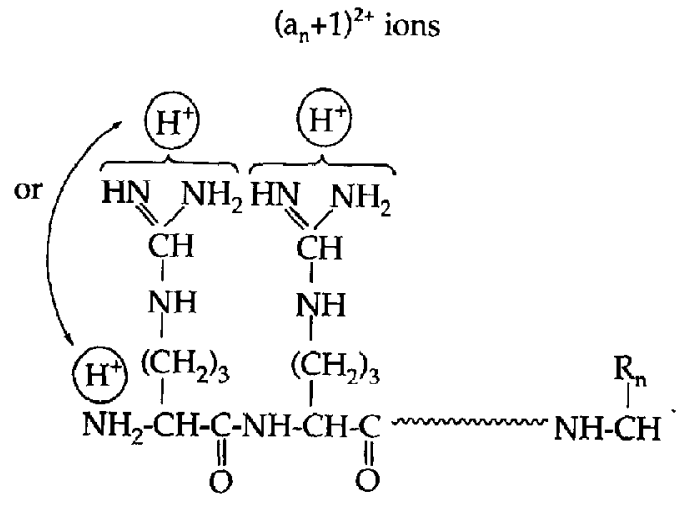

monoisotopic $m / z$ values

\begin{tabular}{|c|c|c|c|}
\hline & calculated & & measured \\
\hline $\begin{array}{l}a_{6} 699.41 \\
a_{8} 933.51 \\
a_{9} 1080.57\end{array}$ & $\begin{array}{l}a_{6}^{2+} 350.21 \\
a_{8}^{2+} 467.26 \\
a_{9}^{2+} 540.79\end{array}$ & $\begin{array}{l}\left(a_{6}+1\right)^{2+} 350.71 \\
\left(a_{B}+1\right)^{2+} 467.76 \\
\left(a_{9}+1\right)^{2+} 541.29\end{array}$ & $\begin{array}{l}350.61 \\
467.61 \\
541.27\end{array}$ \\
\hline
\end{tabular}

Figure 7. Structure of the $\left(a_{n}+1\right)^{2+}$ fragment ions observed in the CID spectrum of the doubly charged precursor ion of peptide RRP(HyP)GFSFFR.

whether some charge migration occurs just prior to fragmentation in the gas phase remains an open question. Nonetheless, it is clear that two charges can reside in close proximity, overcoming possible coulombic repulsion effects, when favored by a high concentration of basic sites. Thus, based on the fragmentation pattern of the doubly charged ions of this study, it appears that the location of charge in the precursor ions is strongly dependent on the primary structure of the peptide and the general observations made for the dissociation of singly charged ions by high-energy CID can be used to rationalize the dissociation of ions with several charges.

An additional feature of the CID spectrum of the $[\mathrm{M}+2 \mathrm{H}]^{2+}$ ion of peptide RRP(HyP)GFSFFR is a predominant fragment peak at $m / z$ 814.7. A peak at $m / z$ 814.7 also is observed in the CID spectrum of the singly charged precursor ion. These peaks could correspond to either a $b_{7}^{+}$or $w_{7}^{+}$ion, both of which have the same mass-to-charge ratio. However, because the other bradykinin-related peptides discussed do not exhibit a corresponding $b_{n}^{+}$fragment ion in their $[\mathrm{M}+$ $\mathrm{H}^{+}$spectra, one must conclude that the ion at $\mathrm{m} / \mathrm{z}$ 814.7 in Figure 6a is a $w_{7}^{+}$ion.

\section{$F^{7}$-Bradykinin}

To confirm that the product of the $(\mathrm{M}+\mathrm{H})^{+}$precursor of the peptide RRP(Hyp)GFSFFR is not a $b_{n}$ ion, the CID spectra of the singly and doubly charged ions for Phe $^{7}$-bradykinin were recorded. Regions of these spectra are shown in Figure 8. An abundant peak at $\mathrm{m} / \mathrm{z}$ 642.7 that corresponds to a $b_{6}^{+}$ion (from cleavage 


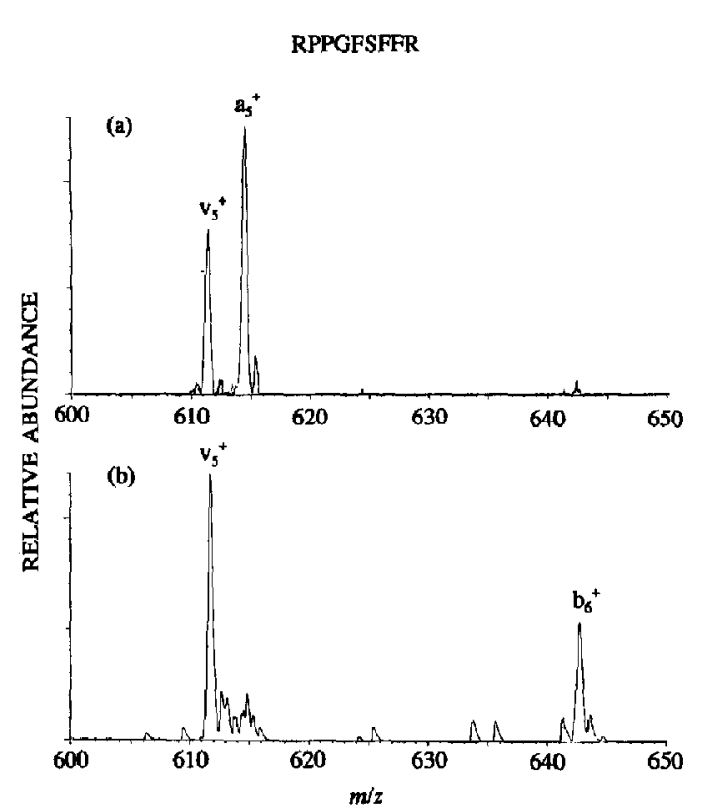

Figure 8. Regions of the CID spectrum of (a) the $[\mathrm{M}+\mathrm{H}]^{+}$and (b) the $[\mathrm{M}+2 \mathrm{H}]^{2+}$ ions of Phe -bradykinin.

between serine and phenylalanine) is present in the spectrum of the doubly charged precursor (Figure $8 \mathrm{~b}$ ), but absent from the CID spectrum of the $[\mathrm{M} / \mathrm{H}]^{+}$ ion (Figure 8a).

Therefore, it appears that it is the presence of the serine residue, and not the residue following serine, that promotes the formation of this $b_{n}$ fragment from the dissociation of the doubly charged peptide ions discussed in the preceding text.

\section{Origin of the $b_{n}^{+}$Product Ions in the CID Spectra of the $[M+2 H]^{2+}$ Precursors}

Although it has been demonstrated above that the serine residue plays an important role in the formation of the $b_{n}^{+}$product ion from the $[\mathrm{M}+2 \mathrm{H}]^{2+}$ precursors for all the peptides studied, several questions conceming this ion remain. What is the role of the serine residue in the formation of the $b_{n}^{+}$ions and are these products formed through charge-remote or charge-directed fragmentation processes? In addition, why are the $b_{n}^{+}$product ions not also observed in the spectra of the singly charged precursors?

In view of the conventional acylium structure proposed for a $b_{n}$ ion, the singly charged $b_{n}^{+}$product ion seen in the CID spectra of all the $[\mathrm{M}+2 \mathrm{H}]^{2+}$ precursors should be formed only when the N-terminally bound proton migrates to the $\mathrm{C}$-terminal portion. However, if the $b_{n}^{+}$ions are produced through homolytic cleavage of the $\mathrm{C}-\mathrm{N}$ bond with transfer of a hydrogen atom to the $C$-terminal portion, then the $C$ terminus of a $b_{n}^{+}$product ion bears no charge. The
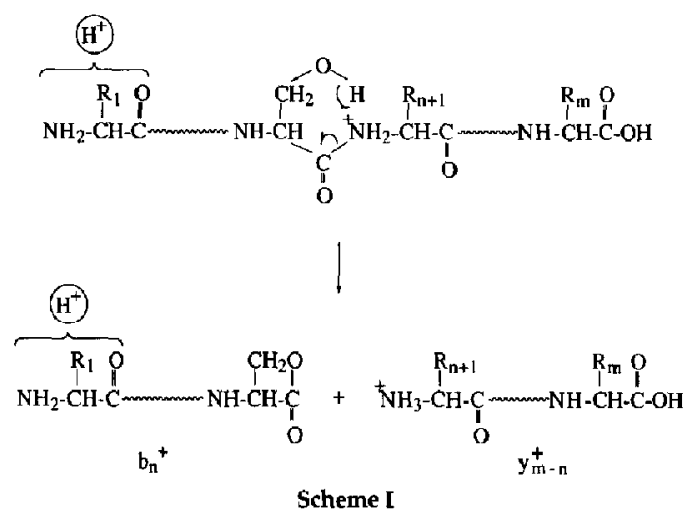

charge on this fragment is instead a consequence of a remotely bound proton toward the $\mathrm{N}$ terminus.

This is not to say that this remotely bound proton promotes the formation of the $b_{n}^{+}$ion through a charge-remote process. Instead, while the first proton of the $[\mathrm{M}+2 \mathrm{H}]^{2+}$ ion directs the fragmentation to produce $\mathrm{N}$-terminal product ions, the second proton can be invoked to promote fragmentation of the backbone in the vicinity of the serine residue through a charge-directed process (Scheme I). Hydrogen migration from oxygen of the side chain of serine accounts for the preferential formation of the $b_{n}^{+}$ion at this residue.

This charge-directed mechanism appears to explain best why $b_{n}^{+}$product ions were not observed in the CID spectra of the singly charged precursors. Product ions of this type are reported to be more prevalent in the spectra of peptides that contain no basic groups [21], unlike those of this study. The mechanism also accounts for the observation that the doubly charged precursor ions exhibit, on occasion, the complementary singly charged $y_{n}$ product ions $[28,29]$, but not $y_{n}^{2+}$ product ions in their CID spectra.

Because all of the peptides in this study contain basic groups, at least one proton in all of the precursors (singly and doubly charged) is highly localized at a basic site. This localization of charge in the $[\mathrm{M}+\mathrm{H}]^{+}$ precursors for all peptides disfavors the formation of $b_{n}$ product ions [21]. The products of these ions are formed primarily though charge-remote processes and their CID spectra afford no $b_{n}$ fragments. In the doubly charged precursors, however, some charge-directed fragmentation may occur, particularly when the most basic groups of the peptide are in close proximity and both charges are not localized at these sites. This is especially evident for des- $R^{9}$-bradykinin, which exhibits several $b_{n}^{+}$and $y_{n}^{+}$product ions. Particularly dominant in this spectrum are the complementary $b_{6}^{+}$ and $y_{2}^{+}$ions, which correspond to cleavage of the backbone at the $\mathrm{C}$-terminal side of serine.

When the two basic sites are more separated in the peptide (as is the case for the remainder of the bradykinin-related peptides) these charge-directed fragmen- 


\section{RVYIHPF}

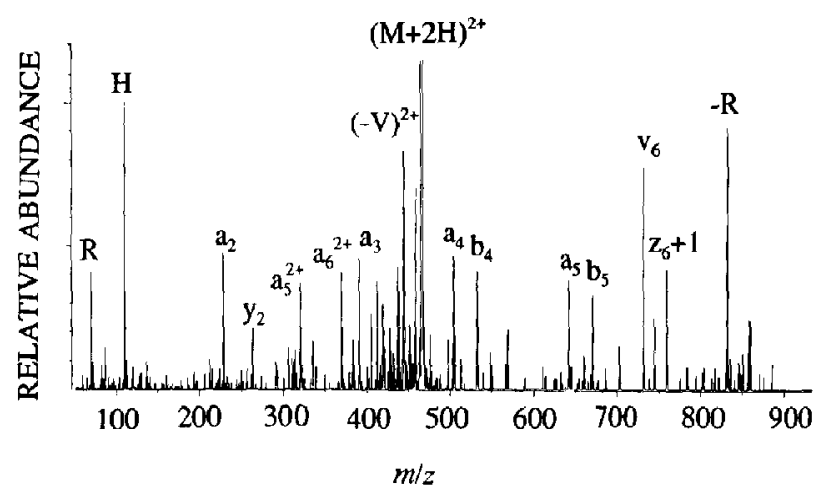

Figure 9. $\mathrm{CID}$ spectrum of the $[\mathrm{M}+2 \mathrm{H}]^{2+}$ ion of angiotensin III (RVYIIPF). tations should be less pronounced. The CID spectra of $[\mathrm{M}+2 \mathrm{H}]^{2+}$ ions for the remainder of the peptides exhibit product ions rationalized through charge-remote fragmentations, although cleavage of the amide bond at serine appears sufficiently facile that this charge-directed pathway is still a dominant process.

\section{Charge State Determination of Fragment Ions Produced from Doubly Charged Precursors}

In our studies of the dissociation of doubly charged ions on a four-sector mass spectrometer, we have made another notable observation. As can be seen from the measured monoisotopic masses for the $\left(a_{n}+1\right)^{2+}$ ions of RRP(HyP)GFSFFR (Figure 7), doubly charged ions on occasion have fractional monoisotopic masses that exceed those predicted for an ion of their size that consists only of $\mathrm{C}, \mathrm{H}, \mathrm{N}$, and $\mathrm{O}$ atoms.
As will be illustrated for the CID spectrum of the $[\mathrm{M}+2 \mathrm{H}]^{2+}$ ion of angiotensin III (Figure 9), it is possible to assign charge states for some fragment ions based solely on the fractional component of their monoisotopic masses. That is, at least for the dissociation of a doubly charged species, sufficient mass accuracy is obtainable so that the charge states of some fragments can be assigned even when the ${ }^{12} \mathrm{C}$-only component of the precursor ion is transmitted through the collision region.

The measured and predicted monoisotopic masses for fragments of the $[\mathrm{M}+2 \mathrm{H}]^{2+}$ ion of angiotensin III are shown in Table 1 . All of the fragment ions observed at mass-to-charge ratios above that of the precursor ion ( $m / z$ 466.41) must be singly charged and are labeled as such in the lower half of Table 1. However, ions with mass-to-charge ratios below that of the precursor ion may be singly or doubly charged.

Table 1. Measured and calculated mass-to-charge ratios values for $\mathrm{CID}$ fragments of the ${ }^{12} \mathrm{C}$-only component of the $[\mathrm{M}+2 \mathrm{H}]^{2+}$ ion of angiotensin [II (see Figure 9 )

\begin{tabular}{|c|c|c|c|c|}
\hline $\begin{array}{c}\text { Measured } \\
\mathrm{m} / \mathrm{z}\end{array}$ & $\begin{array}{c}\text { Predicted } \\
\text { charge state }\end{array}$ & $\begin{array}{l}\text { Calculated } \\
m / 2\end{array}$ & $\begin{array}{c}\text { Difference } \\
\Delta m / 2\end{array}$ & Assignment \\
\hline 70.12 & $1+/ 2+$ & 70.07 & -0.05 & $P$ \\
\hline 110.11 & $1+/ 2+$ & 110.07 & -0.04 & $\mathrm{H}$ \\
\hline 228.27 & $1+/ 2+$ & 228.18 & -0.09 & $a_{2}$ \\
\hline 321.30 & $1+/ 2+$ & 321.20 & -0.10 & $a_{5}^{2+}$ \\
\hline 369.74 & $2+$ & 369.72 & -0.02 & $a_{6}^{2+}$ \\
\hline 391.40 & $1+/ 2+$ & 391.25 & -0.15 & $a_{3}$ \\
\hline 412.30 & $1+/ 2+$ & 412.24 & -0.06 & $(-Y)^{2+}$ \\
\hline 443.77 & $2+$ & 443.73 & -0.04 & $(-v)^{2+}$ \\
\hline 458.29 & $1+/ 2+$ & 458.25 & -0.04 & $\left\{z_{7}+1\right\}^{2+}$ \\
\hline 504.55 & $1+$ & 504.33 & -0.22 & $a_{4}$ \\
\hline 532.32 & $1+$ & 532.32 & 0.00 & $b_{4}$ \\
\hline 641.78 & $1+$ & 641.39 & -0.39 & $a_{5}$ \\
\hline 669.75 & $1+$ & 669.38 & -0.37 & $b_{5}$ \\
\hline 731.68 & $1+$ & 731.35 & -0.33 & $v_{B}$ \\
\hline 759.66 & $1+$ & 759.39 & -0.27 & $z_{6}+1$ \\
\hline 831.85 & $1+$ & 831.43 & -0.42 & $-R$ \\
\hline
\end{tabular}


Two ions observed in this region (at $m / z 369.74$ and 443.77) must be doubly charged because both exhibit high $(>0.5)$ fractional monoisotopic masses. This is a consequence of their singly charged ion counterparts having an even integer monoisotopic mass. The additional proton bound in the case of the doubly charged ion increases the mass of the fragment to an odd integer value, such that its division by two results in a high fractional mass. This is the case for the fragment ions $a_{6}^{2+}(m / z 369.74)$ and $(-V)^{2+}(m / z$ 443.77).

However, a low fractional monoisotopic mass for a fragment ion is not an indication that it is singly charged. All singly charged ions detected below that of the doubly charged precursor will have a low fractional monoisotopic mass, but so too will doubly charged ions whose singly charged counterparts have odd integer masses. As in the case of the $a_{5}^{2+}$ ion, its singly charged analog $a_{5}^{+}$has a monoisopic value of $m / z 641.39$ with an odd integer mass. Thus, the addition of a proton to this fragment results in an ion of $m / z$ 642.39/2 (i.e., 321.20; see. Table 1). Whereas these observations may prove useful to assign fragments of doubly charged ions of relatively small peptides $(<1500 \mathrm{u}$ ), it is unquestionable that the most reliable method to assign the charge state to fragments of a product ion spectrum is to resolve their isotope cluster (or at least the ${ }^{13} \mathrm{C}_{0} /{ }^{13} \mathrm{C}_{1}$ pair) transmitted as the precursor ion beam.

\section{Conclusions}

To the best of our knowledge, this work represents the first detailed study to investigate the effect that the charge state of the precursor ion has on the dissociation of a peptide under high-energy collision conditions. A systematic comparison of the high-energy CID spectra of the singly and doubly charged ions for several basic peptides of similar primary structure has demonstrated that the dissociation behavior of doubly charged ions is strongly influenced by the location of the basic residues within the peptide and that the general observations concerning the fragmentation of singly charged ions at these energies [21] can be extended to precursors with several charges. As borne out by the results presented in this paper, multiply charged peptide ions can provide structurally informative fragment ions when they are collisionally activated under high-energy conditions. It has been shown that the type of fragment ions produced may differ from those formed from the dissociation of the corresponding singly charged precursor ion (see for example Figure 4), although this is not always the case (Figures 2 and 3). Indeed, for peptides bradykinin and des- $\mathrm{R}^{1}$-bradykinin it is demonstrated that the CID spectra of the doubly charged ions are useful for sequencing in view of the fact that they largely mirror the CID spectra of their singly charged counterparts from which their structures can be derived.

We also have shown, based on the dissociation behavior of the doubly charged ions of these peptides, that two charges can reside in close proximity in the precursor ions when they are favored by a high concentration of basic sites, even when more remote basic groups are also present in the molecule. This result challenges the notion that like charges must be well separated in a multiply charged ion to minimize coulombic repulsion effects, particularly when remote sites exist to support the charges. Thus, it appears that the primary structure of a molecule is as important as its size and conformation in determining the number and the location of charges it supports. Indeed, our observation that two charges can reside in close proximity in a proportion of the $[\mathrm{M}+2 \mathrm{H}]^{2+}$ precursor ions for the peptide RRP(HyP)GFSFFR is not explained by a recent model for ion formation during the ESI process [20]. It is important to add, however, that we cannot rule out the possibility that some charge migration occurs prior to the fragmentation of this peptide, even though in this case it would appear to be an energetically unfavorable process.

\section{Acknowledgment}

We are indebted to James A. Hill for constructing the power supply for the electrospray ion source and to Ioannis $\mathrm{A}$. Papayannopoulos for his assistance at the early stages of these investigations. We gratefully acknowledge the financial support of the National Institutes of Health through research grants from the National Institutes of General Medical Sciences (GM05472) and the National Center for Research Resources (RR00317).

\section{References}

1. Hunt, D. F.; Yates, J. R., III; Shabanowitz, J.; Winston, S.; Hauer, C. R. Proc. Natl. Acad. Sci. U.SA. 1986, 83, 6233-6237.

2. Biemann, K. Biomed. Environ. Mass Spectrom. 1988, 16, 99-111.

3. Neumann, G. M.; Derrick, P. J. Z. Naturforsch. 1984, 39a, 584-592.

4. Yamashita, M.; Fenn, J. B. J. Phys. Chem. 1984, 88, 4451-4459.

5. Meng, C. K.; Mann, M; Fenn, J. B. Z. Phys. D 1988, 10 , 361-368.

6. Mann, M.; Meng. C. K.; Fenn, J. B. Anal, Chem. 1989, 61, 1702-1708.

7. Lon, J. A.; Edmonds, C. G.; Smith R. D. Anal. Chem. 1991, 63, 2488-2499.

8. Loo, J. A.; Udseth, H. R.; Smith, R. D. Rapid Commun. Mass Spectrom. 1988, 2, 207-210.

9. Huang, E. C.; Henion, J. D. I. Am. Soc. Mass Spectrom. 1990, 1, 158-165.

10. Hunt, D. F.; Michel, H.; Dickinson, T. A,; Shabanowitz, J.; Cox, A. L.; Sakaguchi, K.; Appella, E.; Grey, H. M.; Sette, A. Science 1992, 256, 1817-1820.

11. Tang, X-J.; Boyd, R. K. Rapid Commun. Mass Spectrom. 1992, $6,651-657$.

12. Tang, X-J.; Thibault, P.; Boyd, R. K. Anal. Chem. 1993, 65, 2824-2834.

13. Senko, M. W.; Beu, S. C.; McLafferty, F. W. Anat. Chem. 1994. $66,415-417$

14. Neumann, G. M.; Derrick, P. J. Aust. J. Chem, 1984, 37, 2261-2277.

15. Barber, M.; Bell, D. J.; Morris, M.; Tetler, L. W.; Woods, M. D.; Monaghan, J. J.; Morden, W. E. Org. Mass Spectrom. 1989, 24, 504-510. 
16. Downard, K. M.; Papayannopoulos, I. A.; Costello, C. E.; Biemann, K. Proceedings of the 41st ASMS Conference on Mass Spectrometry and Allied Topics; San Francisco, CA, 1993; pp $360-361$.

17. Orlando, R. Proceedings of the Kyolo' 92 International Confentuce on Biological Mass Spectrometry; Kyoto, Japan, 1992; pp 180-181,

18. Bateman, R. H.; Bordoli, R. S.; Cashmore, P.; Major, H. J.; Woolfitt, A. R. Proceedings of the 40th ASMS Conference on Mass Spectrometry and Allied Topics; Washington, DC, 1992; pp $1669-1670$.

19. Fabris, D.; Kelly, M.; Murphy, C.; Wu, Z.; Fenselau, C. J. Am. Soc. Mass Spectrom. 1993, 4, 652-661.

20. Fenn, J. B. J. Am. Soc. Mass Spectrom. 1993, 4, 525-535.

21. Johnson, R. S.; Martin, S. A.; Biemann, K. Int. J. Mass Spectrom. Ion Processes 1988, 86, 137-154.
22. Orlando, R.; Fenselau, C. Org. Mass Spectrom. 1991, 26, 664-666.

23. Orlando, R.; Boyd, R. K. Org. Mass Spectrom. 1992, 27, 151-155.

24. Anuan, R. S.; Biemaru, K. J. Am. Soc. Mass Spectrom. 1992, 4, 87-96.

25. Vath, J. E.; Biemann, K. Int. I. Mass Spectrom. Ion Processes 1990, 100, 287-299

26. Stults, J. T. Proceedings of the 40th ASMS Conference on Mass Spectrometry and Allied Topici; Washington, DC, 1992; pp $1815-1816$

27. Burlet, O.; Orkiszewski, R. S.; Ballard, K. D.; Gaskell, S. J. Rapid Commun. Mass Spectrom. 1992, 6, 658-662.

28. Mueller, D. R.; Eckersley, M.; Richter W. J. Org. Mass Spectroin. 1988, 23, 217-222.

29. Kenny, P. T. M.; Nomoto, K.; Orlando, R. Rapid Commun. Mass Spectrom. 1992, 6, 95-97. 